\title{
SOCIAL MEDIA AND ITS INFLUENCE ON VOCABULARY AND LANGUAGE LEARNING: A CASE STUDY
}

\author{
Zahirah Zainal, \\ Noor Hanim Rahmat ${ }^{\mathrm{i}}$ \\ Akademi Pengajian Bahasa, \\ Universiti Teknologi MARA (UiTM), \\ Shah Alam, Malaysia
}

\begin{abstract}
:
Social media is a prominent medium of communication and used by all generations. Besides being used as a tool of communication, institutions have integrated social media such as Twitter, Facebook, and YouTube as learning tools to deliver new information and connect with students. The popularity that social media has gained over the years has become a debate whether social media platforms are effective teaching and learning tool. This study attempts to seek the influence of social media on English vocabulary development among students in public and private universities in Malaysia. This study also aims to explore the influence of social media on interest in language learning skill. Besides, this study investigates how these platforms cause positive and negative influence on language learning. Data and responses for this study are obtained from a questionnaire. The questionnaire data was then analyzed quantitatively using SPSS. The findings revealed that social media sparks language learning interest among English learners.
\end{abstract}

Keywords: social media, vocabulary, language learning, positive impact, negative impact

\section{Introduction}

In recent years, social media platforms have become the medium of everyday interaction. Social media platforms such as Twitter, Instagram, YouTube, Facebook, Skype and many others serve different purposes in communication. These mediums have helped learners of English indirectly as English is widely used on social media. In addition, social media are utilized as a learning tool. Social media is also a place where students share and discuss their academic materials. Studies conducted by researchers found Facebook has greatly impacted second language learning (Derakshan \& Hasanabbasi, 2015). Many

i Correspondence: email patanim@gmail.com, noorh763@uitm.edu.my 
language learning related resources are available on social media. Based on a study carried out by Al-Rahmi and Othman (2013), the findings indicate students' engagement is higher when social media is utilized within the class because social media provides sufficient and up-to-date content. Students also are exposed to interaction with other individuals around the world using social media. A study conducted by Bicen, Sadikoglu and Sadikoglu (2015) revealed that the utilization of social media has positive impacts on learning foreign language. However, a study done by Abbasova (2016) and Kasuma (2017) found that writing skill is negatively affected when using social media.

Social media platforms are perceived as effective tools in language learning. The impacts of social media on second and foreign language acquisition found in a study conducted by Alharthy and Alfaki in 2014 revealed it is more effective to learn via social media compared to traditional learning. Social media expose learners to the most recent style of words use. In addition, social media provides students on the usage of words in an authentic real-life situation. The use of social media also provides positive effects such as pronunciation improvement and vocabulary enlargement resulted from the use of social media (Abbasova, 2016).

However, there are drawbacks over the use of social media on learners' vocabulary such as language used on social network is not entirely correct, and this might affect other users on social media. In addition, the excessive use of internet slangs such as ROFL (roll on floor laugh) and LOL (laugh out loud) will affect the traditional or formal English vocabulary negatively. Moreover, the employment of informal contractions which are short forms of words that people use when speaking casually such as "gonna", whatcha, ain't, gimme, and etc. by users of social media is quite common to see. Informal contractions are not used in writing and "correct speech". Learners might be influenced by the use of informal contractions and apply them in writing. According to Swan (2017) social media has gathered a lot of complaint regarding the negative impact on students' grammar use and spelling.

Social media is no doubt a part of our life and there are mixed views on the effectiveness of social media in improving and widening English skills. Research has to be carried out to find out the influence of social media in English vocabulary development.

This study is aimed to identify the influence of social media on English vocabulary development among university students. Specifically, this study explores how social media influence vocabulary skills. The other is to explore the influence of social media on interest in language acquisition skill. This study also investigates how social media cause positive and negative influence language acquisition learning. The key questions this study aims to find answer to the following questions:

1) How does social media influence English vocabulary development among university students?

2) How does social media influence interest in language acquisition skill?

3) How does social media cause positive and negative influence language acquisition learning? 


\section{Literature Review}

\subsection{Introduction}

Social media is an Internet based technology that is used by most individuals to interact and communicate via gadgets. Facebook, Twitter, YouTube, LinkedIn, and Google are some of social networking platforms that have a big capability in assisting students' learning process by supplying opportunities to gather and access information in order to develop, strengthen and share their knowledge (Gaytan, 2013). Social media are now turning into major medium for entertainment and education .Students utilize social media as a medium of interaction on daily basis. According to Regan (2015) a total of 2,206 billion of active users recorded in 2015 , which resulted in $30 \%$ of global population. It has risen by 176 million users the year before. The use of social networking has been rising, there should be implementation to use social media into learners' English learning process. In this chapter, some reviews on studies that are related to the topic such as vocabulary learning, barriers to language learning, factors for vocabulary acquisition, and the influence of social media on language acquisition are provided (Krashen, 2009).

\subsection{The Use of Language on Social Media}

Different social media platforms serve different feature and service. Due to the distinctness, it affects how people communicate and speak within these platforms. For example, Twitter, Facebook, and Instagram. Twitter is used for quick reading of information, thus encouraging the use of limited word per tweet. Meanwhile Facebook provides much longer writing of messages. On the other hand, Instagram is primarily a picture and video media platform which has no limitations in terms of messages length (Mansor, 2016 and Sebah Al-Ali ,2014)

The growth in popularity of social media creates internet slangs which are known as jargons used on these sites. To express themselves in a quick manner, they use these jargons. However, it can bring negative impacts to many social media users. The usage of internet slangs such as ROFL (roll on floor laugh), BTW (by the way), TTYL (talk to you later), and LOL (laugh out loud) bring worries to some as it might affect the English vocabulary. In some other countries such as Thailand, numbers are used to present the same meaning as LOL which 555 (Jimma, 2017).

English is the universal language and it is constantly changing to accommodate development in technology. Social networks such as Facebook and others play an important role in the acquisition of learning English as a second language. There are numbers of advantages of social media to the learners such as increasing motivation and developing social skill. According to a study conducted by Dhanya (2016) and Namaziandost and Nasri (2019), due to the diverse avenues in which social media have brought, learners are able to enhance their language skills. In addition, social media provides learners with the experience of participating in a relevant, real-time, on-going actual conversation on these social networking sites (Belal, 2014) claims the use of social media reduces anxiety and improves language production. The networking sites are 
well-known among students because they heightened motivation and participation. According to Rahmat (2019), one way to motivate language learner is to provide a conducive learning situation to enhance active learning. This can be done through the use of social media. When students allocate their time on social media such as Facebook as an English learning tool, they learn the language and get to collaborate with individuals worldwide (Rouis, Limayem \& Salehi, 2011) and can accomplish language function without having to meet native speakers in real life through social media.

Social media, however, has the tendency to influence students' English negatively. There is now a trend on social media that could menace literacy ability and skill of students due to the use of abbreviations and uncommon jargon in writing (Craig, 2003). Negative social promotion and negative behavior may develop with the use of Facebook (Fodeman and Monroe as cited in Derakshan \& Hasanabbi, 2015, p.1091). In addition, according to Swan (2017) users of social media have reported the negative impact on students' grammar use and spelling.

Based on the social constructivist model, the process of language learning involved students to participate actively in their own learning process. Social constructivist promotes interaction between individuals in the society. Vygotsky (1987) reported that, cultural and social play important part in intellectual development. In order to achieve a higher cognitive function, there is an involvement of socially supported controlled performance to individually controlled performance, which is known as the transfer from inter-psychological to the intra-psychological. Vygotsky (Kathryn, 1998) claimed through meaningful learning instead of learning through facts, a higher cognitive development can be achieved.

Social media plays a strong role in learners' language acquisition. One significant finding of the positive impact of social media on language learners is learners' confidence, attitude, and motivation improved outstandingly. Learners stated that participation on social media platforms has implanted a more positive attitude in learning English as these mediums have the features that offer them language improvement opportunities (Kabilan et al., 2010). With social media especially Facebook and Twitter, learners are exposed to a wide range of texts. Not only they can have access to review and read different written texts shared by other users, learners also will keep updated of global current issues on Twitter. According to Khan, Ayaz Khan \& Khan (2016) learners will gain an immense quantity of new phrases and words without having to read many books or going to library and learners' overall language skill will be enhanced by the improvement in vocabulary.

The existence of social media has helped people all over the world stay connected by online interaction. This kind of interactivity offers learners to experience the meaningmaking with original content and people which are the native speakers. Learners are also introduced to a variety range of discourse functions thus it improves language ability. This helped to spark creative distribution of language play, and also raise critical literacy (Kasuma, 2017). 
However, social media have gained criticism as teenage learners are too dependent on social media such as Twitter, Facebook, and YouTube. These students rely heavily on open accessible data and info on social media, hence it results to the decreasing in learners' focus and academic performance. Social media helps in connecting learners with individuals across the globe, but as stated by Abbas, Aman, Nurunnabi, \& Bano (2019) the more time learners allocate on social media, the lesser time they spend interacting in person with real people, and it will impact their communication skills.

Although Facebook, Instagram and YouTube have been recognized as part of learning medium, these platforms have negative effects. As an example, Facebook is an online space where users can make use for writing. They can express themselves freely and expose to many written posts, however according to Derakshan \& Hasanabbasi, many of the posts are informal and they are not the same as academic writing that learners apply in language learning setting (2015).

\subsection{Vocabulary Learning}

Vocabulary learning is one of the most challenging items of a language to learn. It is the most vital element of a language. Mastering vocabulary would not only help second language speakers in understanding messages better but making meaningful utterances too. Haddad (2016) and Farjami and Aidinlou (2013) state through speaking, listening, and reading learners indirectly develop vocabulary. Vocabulary development is also influenced by a learner's previous experiences and background knowledge. The process of second language acquisition (SLA), vocabulary plays a crucial role when learners develop the four skills of listening, speaking, reading, and writing. Due to these reasons, vocabulary instruction is an important issue of discussion. (Hasannejad, Bahador \& Kazemi, 2015). Song and Cheng (2017) and Moody, Hu, Kuo, Jouhar, Xu \& Lee (2018) claimed discovery strategies are used to receive the initial information of new words and to understand their lexical meaning, including decision strategies and social strategies. Consolidation strategies are mainly composed of memory strategies, cognitive strategies, and metacognitive strategies.

A systematic review of vocabulary research done by Hairrell, Rupley, and Simmons (2011) stated targeted vocabulary learning leads to an increase of word knowledge. The study found that repeated exposure, contextual analysis, and semantic strategies are three common methods in building up vocabulary. In addition, according to Nagy and Heibert (2011) and Butler, Urrutia, Buenger, Gonzalez, Hunt and Eisenhart (2010) and vocabulary development is also influenced by wide exposure through reading. Frequency of time spent in wide reading, language proficiency, and text complexity are factors that affect the relationship between wide reading and vocabulary development (Ford-Connors and Paratore, 2015).

Online vocabulary learning is usually associated to incidental learning. Results from other academic or non-academic related activities, happens through interaction, problem solving, repetition and observation, and unintentional and unplanned are what define incidental learning. Learners are also exposed and picked up inaccurate forms of 
a language. It is important to educators to be cautious of the outcomes that may influence learners' ability and learning (Kabilan et al., 2010 as cited in Kasuma, 2017).

\subsubsection{Barriers to Vocabulary Learning}

It is known that English is considered as an important language because it is spoken across the globe. Teaching English is deemed as important especially at university level due to many reasons. Vocabulary learning is important because learners who lack vocabulary knowledge usually would lack in other skills such as reading, writing, speaking and listening (Boonkongsaen, 2012). English learners are insecure of limited vocabulary range and it could stop them from using English on daily basis. Besides feeling insecured, there are many obstacles in learning English skills among ESL and EFL learners. Mat and Yunus (2014) and Haddad (2016) stated it is not something new to note that Malaysian students have poor English command. Lack of motivation was noticed as a barrier in learning language skills. One of the most important elements of learners' language achievement is the attitude (Khan, 2016). Motivation and attitude when learning a language are interconnected as these two elements are needed to achieve a successful language learning process (Ellis, 1997; Gardner, 1985 as cited in Mat and Yunus, 2014). Motivation not only within oneself, but from the surrounding also has a great impact on the process of English language learning. In a study done by Kamali, Mostapha and Baki (2012) found the role of peers, teachers, and environment of classroom influenced the use of vocabulary learning strategies among Malaysian ESL students. Supportive and unsupportive parents also could affect learners (Asgari and Mustapha, 2011). Boonkongsaen (2012) stated learners who live with unsupportive parents tend to have less motivation in learning new words.

Insecurities learners are related to language anxiety. Thrang (2012) stated a great concern in the learning of second and foreign language is language anxiety. Tension or nervousness occurs when a language related task is given (Hashemi, 2011). In addition, field of study of an individual may influence students' vocabulary learning strategies use. Bernardo and Gonzales (2009) conducted a study and it was revealed there was a significant difference in the use of social and determination vocabulary language strategies among Filipino students across faculties.

\subsubsection{Factors for Vocabulary Learning}

A study conducted by Susanto and Halim (2016) which aimed to explore the vocabulary learning in the view of vocabulary learning strategies and socio-educational factors. Various aspects of research and theory were covered in the paper, Susanto and Halim (2016) classified vocabulary learning strategies into two main categories. They are strategies for getting meaning and strategies for acquiring words. Strategies for getting meaning consist of guessing from situation or context, using a dictionary, making deductions from the word-form, and linking to cognates. Strategies for acquiring words consist of repetition and rote learning, organizing words in the mind, and linking to existing knowledge. Incidental vocabulary learning would happen when mind is focused 
elsewhere, such as on understanding a text, or using language for communicative purpose. Incidental learning from exposure to texts would be facilitated greatly only if language learners use vocabulary learning strategies. There are about four vocabulary learning strategies that have been proposed by Susanto and Halim (2016), they are guessing meaning form context, using a mnemonic device or the keyword method, vocabulary notebooks, and the last other learner strategies. Checking for a first language cognate, studying and practicing in peer groups, connecting a word to personal experience or previous learning, saying a new word aloud when studying, using verbal and written repetition, and engaging in extended rehearsal. Language learners have not been taught the majority of words, this is the fact. Henceforth vocabulary learning is more likely to be mainly implicit or incidentally happen. Learning strategies should aid both to find the meaning of new word and to consolidate a word once it has been encountered (Limacher, 2015 and Gibbins \& Greenhow, 2016). Thus, language learners should approach independent learning of vocabulary by using a combination of extensive reading and self-study strategies.

An important factor in vocabulary learning is to increase exposure. To increase exposure to words that are familiar and unfamiliar, a learner needs to listen and read as much as possible. Besides, another factor for vocabulary acquisition is depth of processing or involvement. Depth of processing defines as more effort made by a learner to acquire new words, the higher possibility the learner will remember the words. Meanwhile for depth of involvement, learning will happen more easily when a greater involvement is put. Learners' need to study a word, their search for its meaning, and their evaluation of the result are three areas covered in involvement (Smith, 2018). Vocabulary is important to ensure the successful of second language use. This is because without a good range of vocabulary, learners are unable to use functions and structures that they acquired for communication.

\subsection{Past Studies on the Impact of Social Media on Language Learning}

Many studies have shown how social media can be effective in enhancing students' linguistic proficiency including a study carried out by Khan, Ayaz, Khan and Khan (2016) which aimed to examine the social media role in English language vocabulary development at university level. The objectives of the study were (a) to identify different social media sources which EFL learners use at university level in Khyber Pakhtunkhwa, (b) to compare the perspective of male and female EFL learners regarding the use of different social media sources at university level, and (c) to find out the impact of utilization regarding different social media sources on EFL learners' language proficiency at university level. The results found that social media plays a significant role in developing English vocabulary at university level. A majority of 2291 out of 3650 male students agreed that Social Media has a positive effect on EFL learners' English learning proficiency at university level. Meanwhile for female students, 2220 out of 3650 respondents agreed about the positive effect of Social Media sources in English language learning. One of the major findings of the study is the understanding about the correct 
use of social media sources for English language learning enhances the understanding of the English learners. In addition, the result of the study showed that social media helps to enhance the four basic skills of English language i.e. Listening, Speaking, Reading, Writing and similarly, Vocabulary building and Grammar competency of EFL learners.

Another study done by Abbasova (2016) was aimed to explore the impact of social media platforms on students' English proficiency. The study focused on four language skills: listening, speaking, reading, and writing, as well as grammar and vocabulary. The objectives of the study were to explore the impact of social network on students' English language proficiency in Azerbaijan whether it affects their language knowledge negatively or positively. It was also done to determine what language skills were mostly affected. The population of the study consisted of university students studying at private university Khazar, Azerbaijan. A total 104 students (48 male, 56 female) from the schools of Human and Social Sciences, Education, Economics and Management, Engineering and Applied Sciences had taken part in this study. A close-ended questionnaire was tendered and descriptive statistical method was used to analyze the questionnaire. The vocabulary section of the recent study indicated that the $50 \%$ of the respondents agreed that while sharing any message with the public they force themselves to use rich vocabulary. The findings of the grammar section showed that majority of the respondents agreed (strongly agreed 26.92\%; agreed 34.62\%) with the statement that using social networks can improve their grammar. The listening and speaking sections found that $36.54 \%$ of the respondents agreed that they felt confident after having a chat with an English speaker online whereas $33.65 \%$ slightly agreed that they could understand native speakers' pronunciation. The findings of the reading and writing sections indicated that $31.73 \%$ of respondents pointed out that using internet abbreviations sometimes affects students' writing in a negative way. She claimed that interaction on social media helps in improving learners' vocabulary and literacy skills as it gives opportunities to engage with the language

\section{Methodology}

This study made use of quantitative research design. Quantitative research depends on the collection and analysis of numerical data to explain, predict, describe, or control variables of interest (Gay, Mills, \& Airasian, 2009). For this research, quantitative approach was used in order to answer the research questions. Research survey was used because it enables data collection from a large number of individuals, allows for generalizability of results to large populations. It is also versatile in terms of what can be investigated (Mertler, 2018). Population of this study were the students from public and private universities in Malaysia, ranging from semester 1 to 8, from different education backgrounds. This study made use of simple random sampling method. Every individual of a population was chosen randomly.

In order to achieve the objectives of this study, a set of questionnaire with the utilization of Google form was adapted as the medium in collecting the data to assess 
students' perceptions and views on the usage of social media in building up English vocabulary. A questionnaire is a method to collect primary data in which a sample of participants are asked a list of structured questions to elicit reliable responses (Collis \& Hussey, 2014). Reliability statistics showed that the instrument had a cronbach alpha of 811 (table 1). The questionnaire was divided into 2 main sections: 1) Personal background; 2) Social media usage focusing specifically on (a) Vocabulary skill Khan, Ayaz \& Faheem (2016), (b) Language learning interest Khan, Ayaz \& Faheem (2016); and (c) Positive (Tantarang ,2016), and negative impact (Strictland, 2014). Both sections will have a total of 27 questions. Each question will be rated using a 5-point Likert scale ranging from 1 (strongly disagree) to 5 (strongly agree). In order to test existing theory, a questionnaire was used as a means to collect reliable data in a rather deductive approach (Beiske, 2002 and Winters, Winters and Amedee, 2010). The questionnaire data was analyzed quantitatively using SPSS to reveal mean scores.

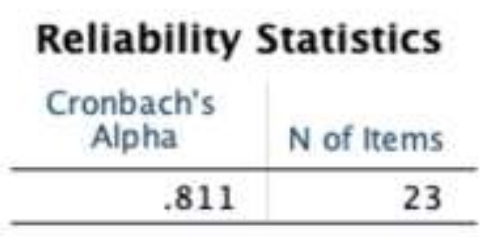

Table 1: Cronbach Alpha

\section{Findings}

This section presents the findings by answering the research questions. The three research questions are;

1) How does social media influence English vocabulary development among university students?

2) How does social media influence interest in language acquisition skill?

3) How does social media cause positive and negative influence language acquisition learning?

\subsection{Findings for Vocabulary Skills}

According to Khan, Ayaz \& Faheem (2016), two main vocabulary skills are knowing (a) new words (b) word functions. More often than not, learners may need help in discovering new words. Knowing word functions is important for learners as they can further aid in the association between the different functions of words used in different contexts.

With reference to Figure 1, the highest mean (4.5) is showing learners would "search for meaning of word" they do not know in social media. Next students also agreed that they "know how to use /apply new words obtained on social media" (4.2). In addition to that, students felt that "social media helped them enhance their language skills" (4.2). 


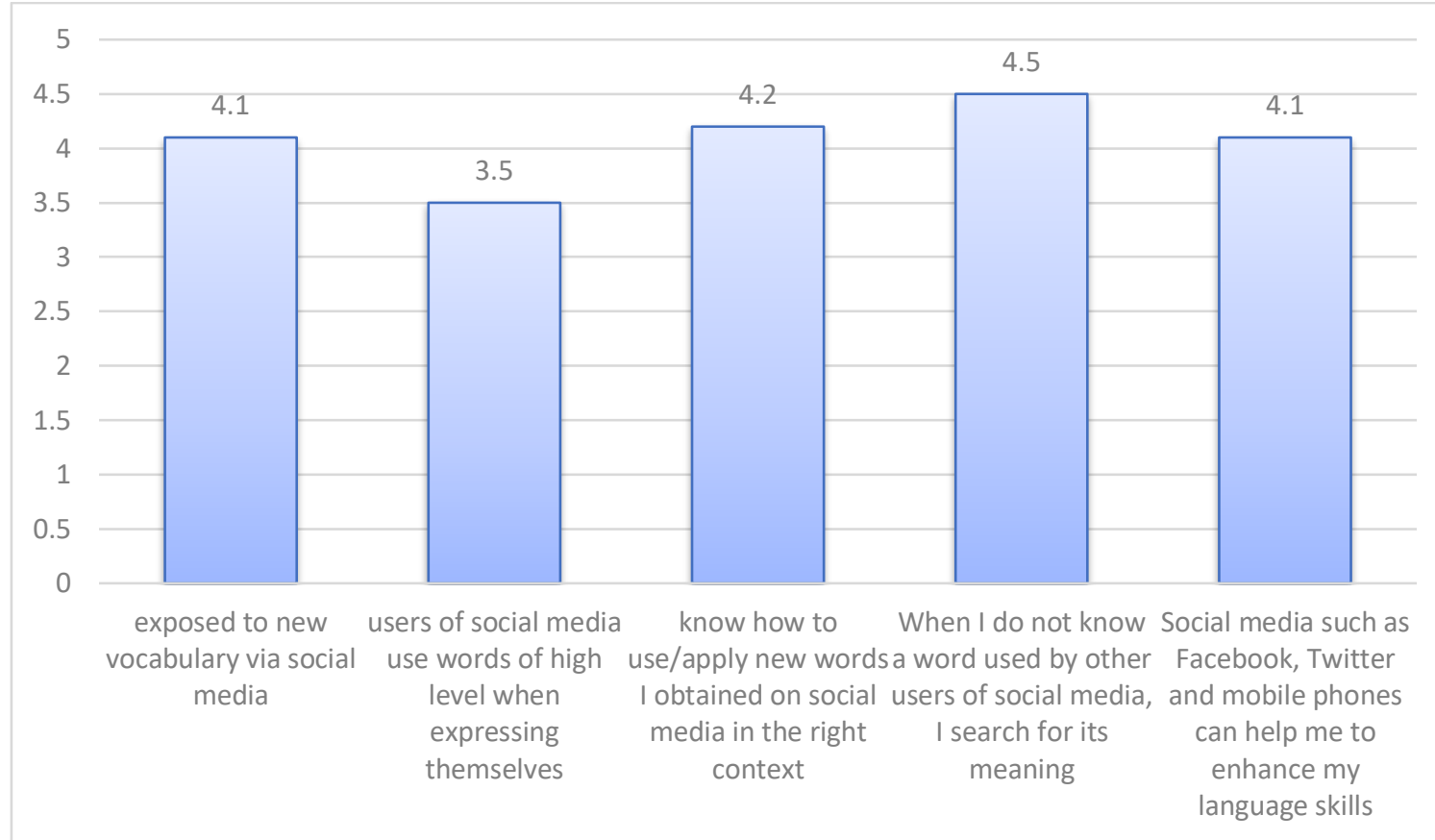

Figure 1: Mean Score for Vocabulary Skills

\subsection{Findings for Language Learning Interest}

According to Khan, Ayaz \& Faheem (2016), when learners are interested to lean a language, this interest may then spark more interest to use the language. This may also spark the need to understand the whole message (instead of partial understanding). This would then create interest for the learners to use the language outside of the classroom.

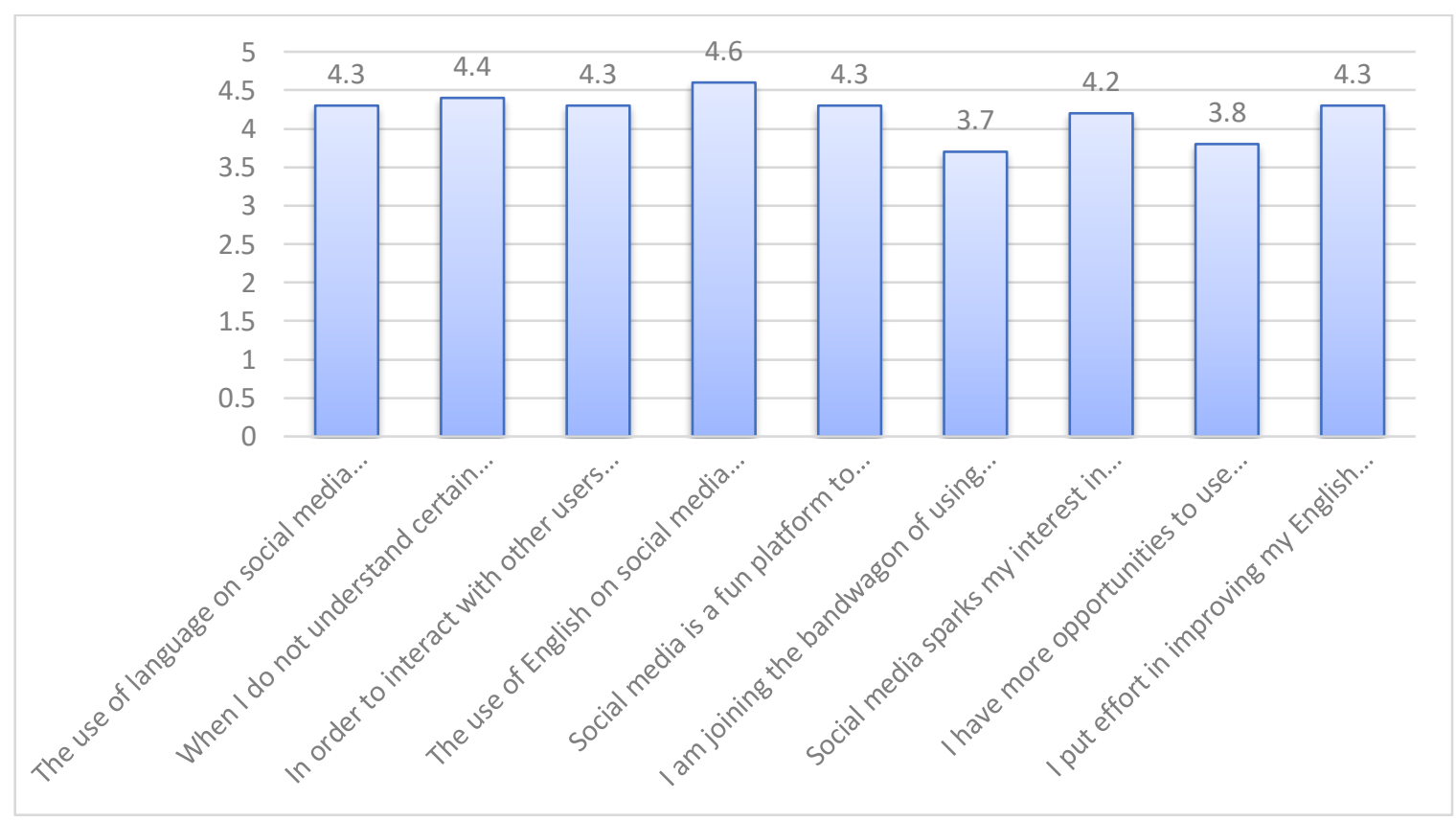

Figure 2: Mean Score for Language Learning Interest 


\subsection{Findings for Positive and Negative Impact}

According to Tantarang (2016), social media create popular impacts such as using authentic English. Social media also provide a platform for users to encourage one another to use English. However, the excessive use of excessive of short forms is one example of a negative outcome from the use of English in social media. In addition to that, Strickland (2014), reported that the use of English in the social media has also caused anxiety among users.

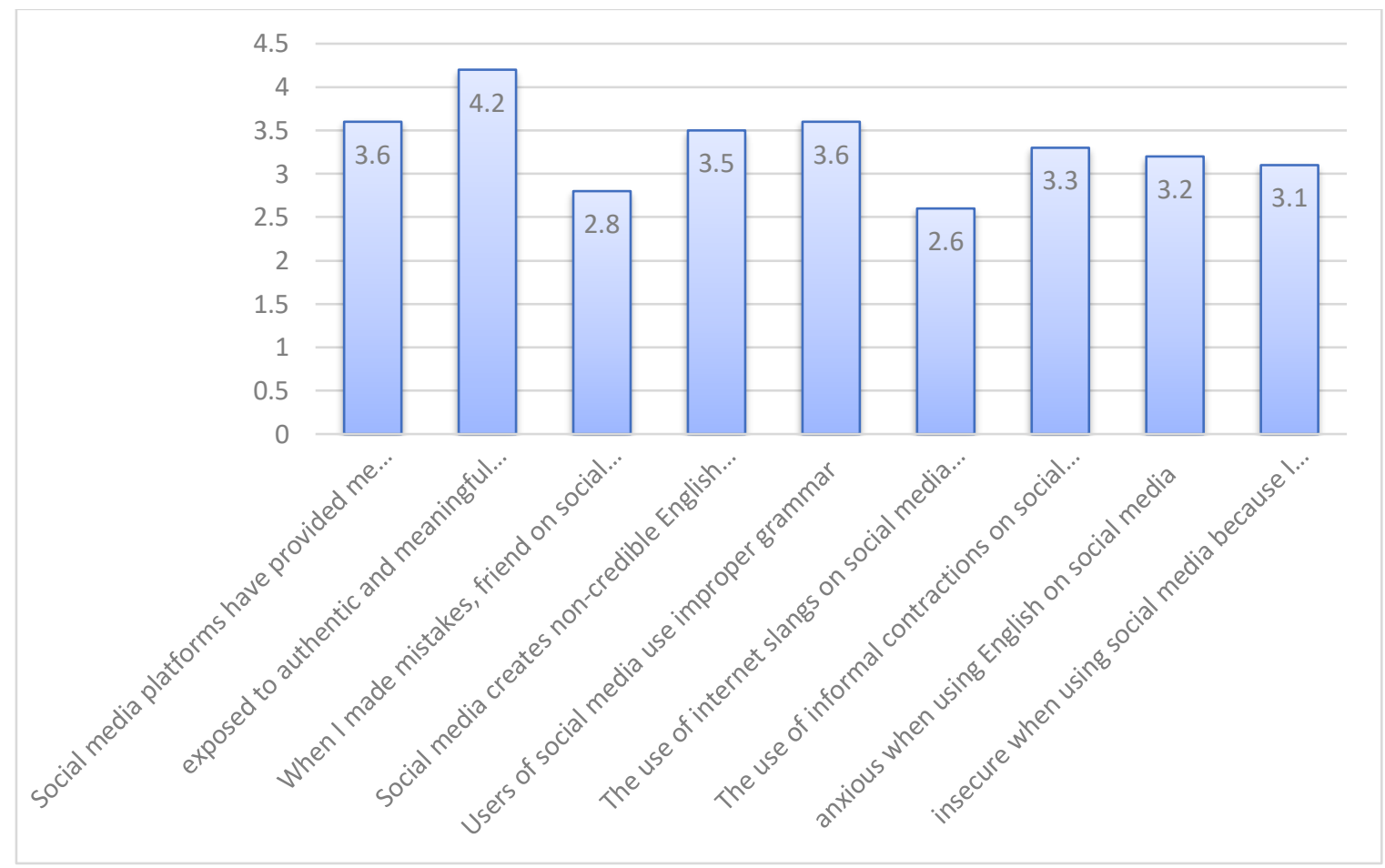

Figure 3: Mean Score for Positive and Negative Impact

Figure 3 presents the mean score for positive and negative impact. The highest mean (4.2) is for "exposed to authentic and meaningful English materials". Lowest (3.1) "insecure when using social media because they have limited vocabulary" and (3.2) anxious when using English on social media".

\section{Conclusion}

\subsection{Summary of Findings and Discussion}

\subsubsection{Vocabulary Skills}

The vocabulary skills section of the study indicates that respondents obtained new words from the use of social media. Many agreed they are exposed to new vocabulary via social media. According to Abbasova (2016) interaction on social media helps in improving learners' vocabulary and literacy skills as it gives opportunities to engage with the language. Respondents agreed that they knew how to apply new words they obtained on social media in the right context. A study done by Khan, Ayaz, Khan and Khan (2016) 
also stated the correct use of social media sources for English language learning enhances the understanding of English learners. Majority of respondents agreed that when they do not know a word used by other users of social media, they would search for the meaning. In addition to that, many also agreed that social media such as Facebook, Twitter and mobile phones can help them to enhance their language skills. According to a study conducted by Dhanya (2016), due to the diverse avenues in which social media have brought, learners are able to enhance their language skills. Overall, the above findings show positive influence of social media on learners' vocabulary skills.

\subsubsection{Language Learning Interest}

The findings of language learning interest section show that respondents agreed that the use of language on social media has encouraged them to write in English better. Moreover, many also agreed that the use of English on social media motivates them to use English more frequently. Some agree that they are joining the bandwagon of using English because most social media users use English. According to Kabilan et al (2010) claim were made by learners that using Facebook has motivated them to apply English more since many writings or posts are in English. The statement of social media is a fun platform to practice English is strongly agreed many respondents and they also agreed that social media sparked their interest in improving English vocabulary. Only some disagreed that they put effort in improving their English in order to communicate and express themselves on social media. According to Namaziandost and Nasri (2019), social media platforms such as Facebook, Twitter, YouTube, and Instagram are remedy for language learners as they are interactive, flexible, and entertaining. These platforms not only provide an opportunity for learners to express themselves in a more confident way but also give learners a chance to practice the language because of the helpful and motivating environment. Some agreed that they have more opportunities to use English on social media rather in classroom. As stated by Rouis et al. when students allocate their time on social media such as Facebook as an English learning tool, they learn the language and get to collaborate with individuals worldwide (2011).

\subsubsection{Positive and Negative Impact}

The positive and negative impact section of this study indicates that the respondents claimed that social media have provided them with proper grammar usage. Half of them also agreed that they are exposed to authentic and meaningful English materials such as videos, posts, captions, and tweets. According to Khan, Ayaz Khan \& Khan (2016) learners will gain an immense quantity of new phrases and words without having to read many books or going to library. Majority of the respondents felt that social media created non-credible English information. Swan (2017) found social media have gathered a lot of complaint regarding the negative impact on students' grammar use and spelling. Next, some respondents agreed that the use of internet slangs (such as LOL, BTW and, FTW) on social media impacts their formal writing and most of the respondents agreed that the use of informal contractions on social media (such as gonna, whatcha, and gimme) affect 
their speaking and writing style. Many of the posts are informal and they are not the same as academic writing that learners apply in language learning setting (Derakshan \& Hasanabbasi, 2015). Interestingly, the respondents reported that they were not anxious using English on social media.

\subsection{Implications and Future Research}

The main objective of this study was to find out the influence, benefits and drawbacks of usage social media to English learners' language vocabulary skill. The findings of this study provide can be concluded that social media sparks language learning interest among students. Collaborative learning using social media can be taken into consideration by universities' management. Lecturers can integrate social media in language learning process to make it more exciting for learners. Many respondents claimed negative impacts of social media. Perhaps learners should be selective at choosing reading materials, in order to make social media a more credible platform for English learning.

Future research should include more methods of gathering information, for instance include a bigger scale number of respondents from different background fields of study and include more universities. Future studies also may come out with more accurate ways to gather data in order to support findings validity. Another area for future research would be collecting responses from high school students as they also are well exposed to Internet and social media. Future research may study on each section included in this study separately.

\section{About the Author(s)}

Zahirah Zaunal is a student at the Akademi Pengajian Bahasa, Universiti Teknologi MARA, Malaysia, doing Bachelor of Applied Language Studies (English for Professional Communication.

Noor Hanim Rahmat is a lecturer at the Akademi Pengajian Bahasa, Universiti Teknologi MARA, Malaysia. She has taught for the past 26 years. Her area of research is TESL, language proficiency, language studies, educational psychology and academic writing.

\section{References}

Abbas, J., Aman, J., Nurunnabi, M., \& Bano, S. (2019). The Impact of Social Media on Learning Behavior for Sustainable Education: Evidence of Students from Selected Universities in Pakistan. Journal Sustainability, 11, p.1-23.

Abbasova, M. (2016). The Impact of Social Networks on the Students' English Language in Azerbaijan. International Multidisciplinary Scientific Conferences on Social Sciences and Arts, 3. Retrieved 14 June, 2019 from https://www.researchgate.net/publication/307967123 The Impact of Social Net works on the Students' English Language in Azerbaijan. 
Alharty, K. \& Alfaki, I. M. (2014). Towards a Digital World: Using Social Networks to Promote Learner's Language. Towards a Digital World: Using Social Networks to Promote Learner's Language, 4(10), p.105-114. Retrieved 14 June, 2019 from http://www.aijcrnet.com/journals/Vol 4 No 10 October 2014/13.pdf.

Alqahtani, M. (2015). The importance of vocabulary in language learning and how to be taught. International Journal of Teaching and Education, Vol. III(3), pp. 21-34.

Al-Rahmi, W. M. \& Othman, M. O. (2013). Evaluating Student's Satisfaction of Using Social Media Through Collaborative Learning in Higher Education. International Journal of Advances in Engineering E Technology. 6(4), p.1541-1551.

Anankulladetch, P. (2017). The Impact of Social Media on ESL Students Learning Performance. Capstone Projects and Master's Theses. 135. Retrieved from https://digitalcommons.csumb.edu/caps thes all/135.

Asgari, A. \& Mustapha, G. B. (2011). The Influence of Informal Language Learning Environment (Parents and Home environment) on the Vocabulary Learning Strategies. English Language and Literature Studies, 1(1), p.7-13.

Belal, A. (2014). Influence of digital social media in writing and speaking of tertiary level student, Department of English and Humanities Brac University, p. 1-36

Bernardo, A. S. \& Gonzales, T. H. (2009). Vocabulary Learning Strategies of Filipino College Students Across Five Disciplines. TESOL Journal, 1, 17-27.

Beiske, B. (2002). Research methods. Uses and limitations of questionnaires, interviews, and case studies. Munich, GRIN Verlag, https://www.grin.com/document/15458

Bicen, H., \& Sadikoglu, S., \& Sadikoglu, G. (2015). The impact of social networks on undergraduate students learning foreign language. Procedia: Social and Behavioral Sciences, 186, 1045-1049.

Boonkongsaen, N. (2012). Factors Affecting Vocabulary Learning Strategies: A Synthesized Study. Naresuan University Journal, 20(2), p. 45-53.

Butler, S., Urrutia, K., Buenger, A., Gonzalez, N., Hunt, M., \& Eisenhart, C. (2010). A Review of the Current Research on Vocabulary Instruction. National Reading Technical Assistance Center, RMC Research Corporation, p. 1-19. Retrieved May 16, 2020 from https://www2.ed.gov/programs/readingfirst/support/rmcfinal1.pdf

Collis, J. and Hussey, R. (2014). Business Research. A Practical Guide for undergraduate and postgraduate students. Cornwall: Palgrave Macmillan.

Derakshan, A. \& Hasanabbasi, S. (2015). Social Networks for Language Learning. Theory and Practice in Language Studies, 5(5), p.1090-1095. Retrieved from http://dx.doi.org/10.17507/tpls.0505.25.

Dhanya, G. (2016). Influence of Social Media on English Language Learning. Journal of English Language and Literature, 3(1), p.105-110. Retrieved 16 June, 2019 from http://joell.in/wp-content/uploads/2016/03/INFLUENCE-OF-SOCIALMEDIA.pdf.

Farjami, F. \& Aidinlou, N. A. (2013). Analysis of the Impediments to English Vocabulary Learning and Teaching. International Journal of Language and Linguistics. Special Issue: Language Teaching and Learning Key Principles (LTLKP). 1(4) pp. 1-5. 
Ford-Connors, E., \& Paratore, J. R. (2015). Vocabulary instruction in fifth grade and beyond: Sources of word learning and productive contexts for development. Review of Educational Research, 85(1), p.50-91. Retrieved 5 May, 2019 from https://journals.sagepub.com/doi/10.3102/0034654314540943.

Gay, L. R., Mills, G. E. and Airasian, P. (2009) Educational Research Competencies for Analysis and Applications. Pearson, Columbus.

Gaytan, J. (2013). Integrating social media into the learning environment of the classroom: Following social constructivism principles. Journal of Applied Research for Business Instruction, 11(1), 1

Gibbins, T., \& Greenhow, C. (2016). students' out of school writing practices in an educational Facebook application. In I. R. Association (Ed.), Social Media and Networking: Concepts, Methodologies, Tools and applications. p.1011-1027.

Haddad, R. H. (2016). Developing Learner Autonomy Learning in classroom: How and Why can it be fostered? Social and Behavioral Sciences, 232, p.784-791.

Hairrel, A., Rupley, W., Simmons, D. (2011). The State of Vocabulary Research. Literacy Research and Instruction. 50(4), p.253-271. Retrieved 10 June, 2019 from https://www.tandfonline.com/doi/full/10.1080/19388071.2010.514036?scroll=top\& n edAccess=true.

Hasannejad, M. R., Bahador, H. \& Kazemi, S. A. (2015). Powerful Vocabulary Acquisition Through Texts Comparison. International Journal of Applied Linguistics E English Literature. 4(2),

Hashemi, M. (2011). Language Stress and Anxiety among the English Language Learners. Social and Behavioral Sciences, 30, p.1811-1816.

Hiebert, E., Scott, J., Castaneda, R., \& Spichtig, A. (2019). An analysis of the features of words that influence vocabulary difficulty. Education Sciences, 9(1), 8.

Jimma, J., D. (2017). Language of social media: Examination of English as a Lingua Franca in social media. University of Iceland School of Humanities Department of English. P.1 32. Retrieved $7 \quad$ February, 2020 at https://skemman.is/bitstream/1946/27228/1/Language\%20of\%20social\%20media \%2 \%20J\%C3\%B3hann\%20Dan\%C3\%ADel\%20Jimma.pdf

Kabilan M. K. et al., (2010). Facebook: An Online Environment for Learning of English in Institutions of Higher Education? Internet and Higher Education. 13, p. 179-187.

Kamali, S., Mostapha, G., B. \& Baki, R., B. (2012). The Influence of Formal Language Learning Environment on Vocabulary Learning Strategies. Journal of Language Teaching and Research, 3(1), p.23-29

Kasuma, S. A. A. (2017). Using Facebook for English Language Learning: the differences among gender and ethnicity. Journal of Nusantara Studies 2017, Vol 2(1), p.177193. Retrieved $14 \quad$ June, 2019 https://journal.unisza.edu.my/jonus/index.php/jonus/article/view/49/116 
Khan, I. U. \& Ayaz, M. \& Faheem, M. (2016). The Role of Social Media in Development of English Language Vocabulary at University Level. International Journal of Academic Research in Business and Social Sciences, 6(11), p.590-604

Khan, I. U., Ayaz, M., Khan, S., Shah, S. F. \& Ullah, M. (2016) Facebook Effect on Enhancement of English Learners' Writing Approach at University Level in Khyber Pakhtunkhwa, K. Journal of Literature, Languages and Linguistics, 28, p.4253.

Kathryn, H., A. (1998). Social Constructivism and the School Literacy Learning of Students of Diverse Backgrounds. Journal of Literacy Research. 30(2), p.297319.

Krashen, S. D. (2009). Principles and Practice in Second Language Acquisition. University of Southern California. Pergamon Press Inc.

Limacher, U. (2015). Language acquisition versus language learning. Retrieved 14 June, 2019 from http://www.utesinternationallounge.com: http://www.utesinternationallou nge.c $\mathrm{m} /$ language-acquisition-versus-language-learning/

Mansor, N. (2016). Enhancing Communication Via Social Media in ESL Classroom. $6^{\text {th }}$ International Conference on Language, Education, and Innovation, p.140-146. Retrieved May 17, 2020 from https://icsai.org/procarch/6iclei/6iclei-052.pdf

Mertler, C. A. (2018). Introduction to Educational Research. Arizona State University, USA.

Mat, C. S. S and Yunus, M. M, Attitudes and Motivation Towards Learning English Among FELDA School Students. Aust. J. Basic \& Appl. Sci., 8(5): 1-8, 2014.

Moody, S., Hu, X., Kuo, L., Jouhar, M., Xu. Z., \& Lee, S. (2018). Vocabulary Instruction: A Critical Analysis of Theories, Research, and Practice. Department of Teaching, Learning, and Culture, Texas AEM University. (8) p. 1-22. Doi:10.3390/educsci8040180.

Nagy, W. E.; Hiebert, E. H. (2011). Toward a theory of word selection. In Handbook of Reading Research; Kamil, M. L., Pearson, P. D., Moje, E. B., Afflerbach, P. P., Eds.; Longman: New York, NY, USA,(4), pp. 388-404.

Namaziandost, E. \& Nasri, M. (2019). The Impact of Social Media on EFL Learners' Speaking Skill: A Survey Study Involving EFL Teachers and Students. Journal of Applied Linguistics and Language Research, 6(3), p.199-215.

Rahmat, N. H. (2019) Cycle of Fear in learning: The Case for Three language Skills. American Journal of Social Sciences and Humanities. Vol 4(1), pp 151-162 Retrieved from http://www.onlinesciencepublishing.com/welcome/htmlarticle/22/324/.

Regan, K. (2015). 10 Amazing Social Media Growth Stats From 2015. Social Media Today. Retrieved from http://www.socialmediatoday.com/social-networks/kadieregan/201508-10/10-amazing-social-media-growth-stats-2015.

Rouis, S., Limayem, M., \& Salehi-Sangari, E. (2011). Impact of Facebook Usage on Students' Academic Achievement: Role of self-regulation and trust. Electronic Journal of Research in Educational Psychology, 9(3), 961-994. 
Sebah Al-Ali. (2014). Embracing the Selfie Craze: Exploring the Possible Use of Instagram as a Language Learning Tool. Issues and Trends in Educational Technology, 2(2), p.116.

Smith, S. (2018). Learning Vocabulary. Retrieved June 14, 2019, from https://www.eapfoundation.com/vocab/learn/.

Song, M. \& Chen, L. (2017). A Review on English Vocabulary Acquisition and Teaching Research in Recent 30 Years in China. Science Journal of Education. 5(4): 174180 http://www.sciencepublishinggroup.com/j/sjedu

doi: 10.11648/j.sjedu.20170504.18.

Susanto, A. Halim, A. F. (2016). English Vocabulary Acquisition through Vocabulary Learning Strategy and Socio-Educational Factors: A Review. Applied Science and Technology, 1,(1). P.166-172. Retrieved at 23 November, 2019 from http://www.estech.org

Swan, K. (2017). Gaining Perspective: Social Media's Impact on Adolescent Literacy Development, Education and Human Development Master's Theses, 767, p.1-41.

Thrang, T. T. (2012). A Review of Horwitz, Horwitz and Cope's Theory of Foreign Language Anxiety and the Challenges to the Theory. English Language Teaching, 5(1), p. 69-75. doi:10.5539/elt.v5n1p69.

Winters, R., Winters, A., Amedee, R. G. and Ochsner, J. (2010). Statistics: A brief overview. The Ochsner Journal (10) p.213-216, Retrieved June 14, 2019 from https://www.researchgate.net/publication/51156953 Statistics A Brief Overviw.

You, Y. (2011). Factors in Vocabulary Acquisition through Reading. ITJ, 8(1), p.43-57. Retrieved June 14, 2019, from https://journals.iupui.edu/index.php/intesol/article/download/15524/15570/21995 \#: :text=A\%20variety\%20of\%20factors\%20affect,better\%20grasp $\% 20 \mathrm{a} \% 20$ word $\%$ 20meaning. 

to copy, distribute, transmit or adapt the article content, providing a proper, prominent and unambiguous attribution to the authors in a manner that makes clear that the materials are being reused under permission of a Creative Commons License. Views, opinions and conclusions expressed in this research article are views, opinions and conclusions of the author(s). Open Access Publishing Group and European Journal of Education Studies shall not be responsible or answerable for any loss, damage or liability caused in relation to/arising out of conflicts of interest, copyright violations and inappropriate or inaccurate use of any kind content related or integrated into the research work. All the published works are meeting the Open Access Publishing requirements and can be freely accessed, shared, modified, distributed and used in educational, commercial and non-commercial purposes under a Creative Commons Attribution 4.0 International License (CC BY 4.0). 